\title{
Chemical Instability and Promiscuity of Arylmethylidenepyrazolinone-Based MDMX Inhibitors
}

\author{
Jakub Stefaniak, ${ }^{\dagger} \ddagger, \S \odot$ Andrew M. Lewis, ${ }^{\dagger, \ddagger}$ Daniel Conole, ${ }^{\S}$ Sébastien R. G. Galan, ${ }^{\S}$ \\ Carole J. R. Bataille, ${ }^{\S}$ Graham M. Wynne, ${ }^{\S} \|^{\|}$M. Paola Castaldi, ${ }^{\perp} \odot$ Thomas Lundbäck, ${ }^{\#}$ \\ Angela J. Russell, ${ }^{*},, \|$ and Kilian V. M. Huber ${ }^{*, \dagger, \neq(i)}$ \\ ${ }^{\dagger}$ Structural Genomics Consortium, Nuffield Department of Medicine, University of Oxford, Oxford, United Kingdom \\ ${ }_{\text {}}$ Target Discovery Institute, Nuffield Department of Medicine, University of Oxford, Oxford, United Kingdom \\ ${ }^{\S}$ Department of Chemistry, Chemistry Research Laboratory, University of Oxford, Oxford, United Kingdom \\ "Department of Pharmacology, University of Oxford, Oxford, United Kingdom \\ ${ }^{\perp}$ Discovery Sciences, IMED Biotech Unit, AstraZeneca, Waltham, Massachusetts 02451, United States \\ \#Discovery Sciences, IMED Biotech Unit, AstraZeneca, Gothenburg, Sweden
}

\section{Supporting Information}

ABSTRACT: Targeting the protein-protein interaction between p53 and MDM2/MDMX (MDM4) represents an attractive anticancer strategy for the treatment of p53competent tumors. Several selective and potent MDM2 inhibitors have been developed and entered the clinic; however, the repertoire of MDMX antagonists is still limited. The arylmethylidenepyrazolinone SJ-172550 has been reported as a selective MDMX antagonist; yet, uncertainties about its mechanism of action have raised doubts about its use as a chemical probe. Here, we show that, in addition to its unclear mode of action, SJ-172550 is unstable in aqueous buffers, giving rise to side products of unknown biological activity. Using an SJ-172550-derived affinity probe, we observed promiscuous binding to cellular proteins whereas cellular thermal shift assays did not reveal a stabilizing effect on MDMX. Overall, our results raise further questions about the interpretation of data using SJ-172550 and related compounds to investigate cellular phenotypes.
$\mathrm{D}$ ubbed "the guardian of the genome", the tumor suppressor p53 is a transcription factor that is activated in response to genotoxic, hypoxic, or oncogenic signals. ${ }^{2}$ In turn, it mediates cell cycle arrest, ${ }^{3}$ senescence, or apoptosis in normal cells. ${ }^{4}$ In cancer, p53 is a critical barrier against oncogenesis as an estimated $50 \%$ of all tumors harbor p53 mutations. ${ }^{5}$ Alternatively, p53 function is often suppressed through undesirable activation of upstream regulators. ${ }^{6}$ Two examples of such regulators include members of the murine double-minute family MDM2 and MDMX (MDM4), which bind to 553 preventing its transcriptional activity, as well as (in the case of MDM2) targeting it for proteasomal degradation. ${ }^{7,8}$ Blocking the interaction between MDM2 and p53 is a viable strategy for p53 activation, ${ }^{9,10}$ and several potent MDM2 inhibitors $^{11-13}$ have been identified, with Nutlin-3a as a prominent example. ${ }^{14}$ MDMX is postulated to play a compensatory role when MDM2 is inhibited, ${ }^{15}$ which suggests that a dual MDM2/MDMX or selective MDMX inhibitor could help to more fully understand the interplay between these proteins and p53, and may ultimately lead to novel anticancer drugs.

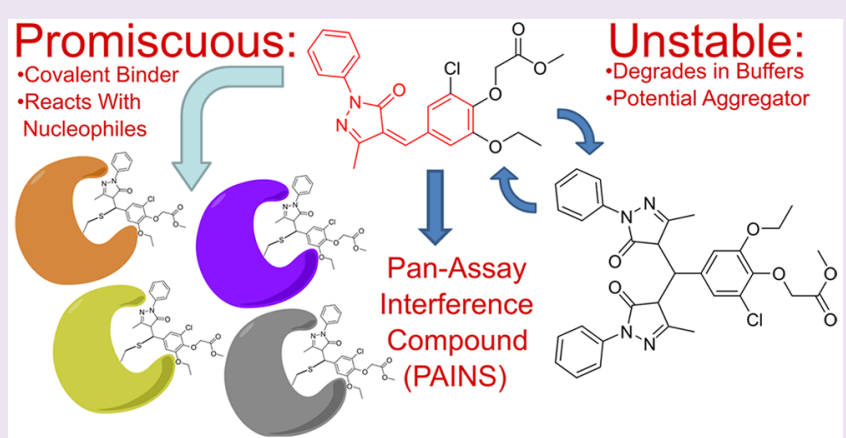

SJ-172550 (1; see Figure 1A, left) was discovered using an in vitro fluorescence polarization (FP)-based high-throughput screen as a potent $\mathrm{MDMX}$ inhibitor with an $\mathrm{EC}_{50}$ value of $0.84 \mu \mathrm{M} .{ }^{16}$ Further data suggested that 1 could potentiate the cytotoxic effects of Nutlin-3a in MDMX-overexpressing cell lines and that the compound, despite the presence of an electrophilic Michael acceptor moiety, acts in a noncovalent manner. ${ }^{16}$ However, a subsequent follow-up study revealed that SJ-172550 does bind MDMX covalently with the benzylidene-5-pyrazolone scaffold undergoing a conjugate addition with free thiols on cysteine residues. ${ }^{17}$ Binding of 1 to MDMX was also strongly attenuated under reducing conditions, thereby raising the following question: is SJ172550 actually able to engage MDMX in cells? Despite only limited data availability on the direct interaction of $\mathbf{1}$ and MDMX in living cells, the compound finds frequent use as a tool in numerous publications, ${ }^{18-20}$ because of its first-in-class

Received: July 16, 2018

Accepted: September 14, 2018

Published: September 14, 2018 
A<smiles>CCOc1cc(/C=C2/C(=O)N(c3ccccc3)N=C2C)cc(Cl)c1OCC(=O)OC</smiles>

Molecular Weight: 428.87<smiles>CCOc1cc(CC2C(=O)N(c3ccccc3)N=C2C)cc(Cl)c1OCC(=O)OC</smiles>

Molecular Weight: 430.89

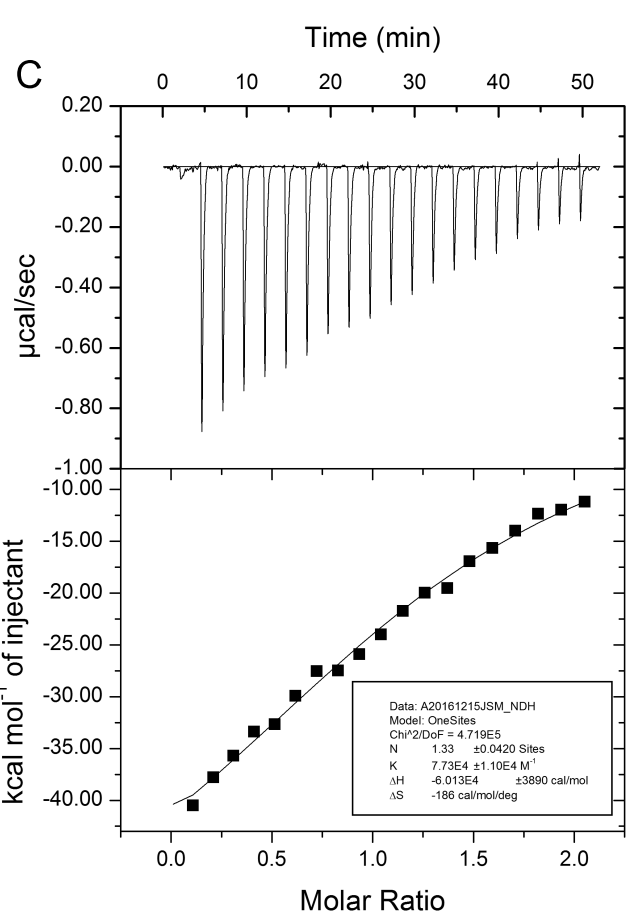

$\mathrm{D}$

B
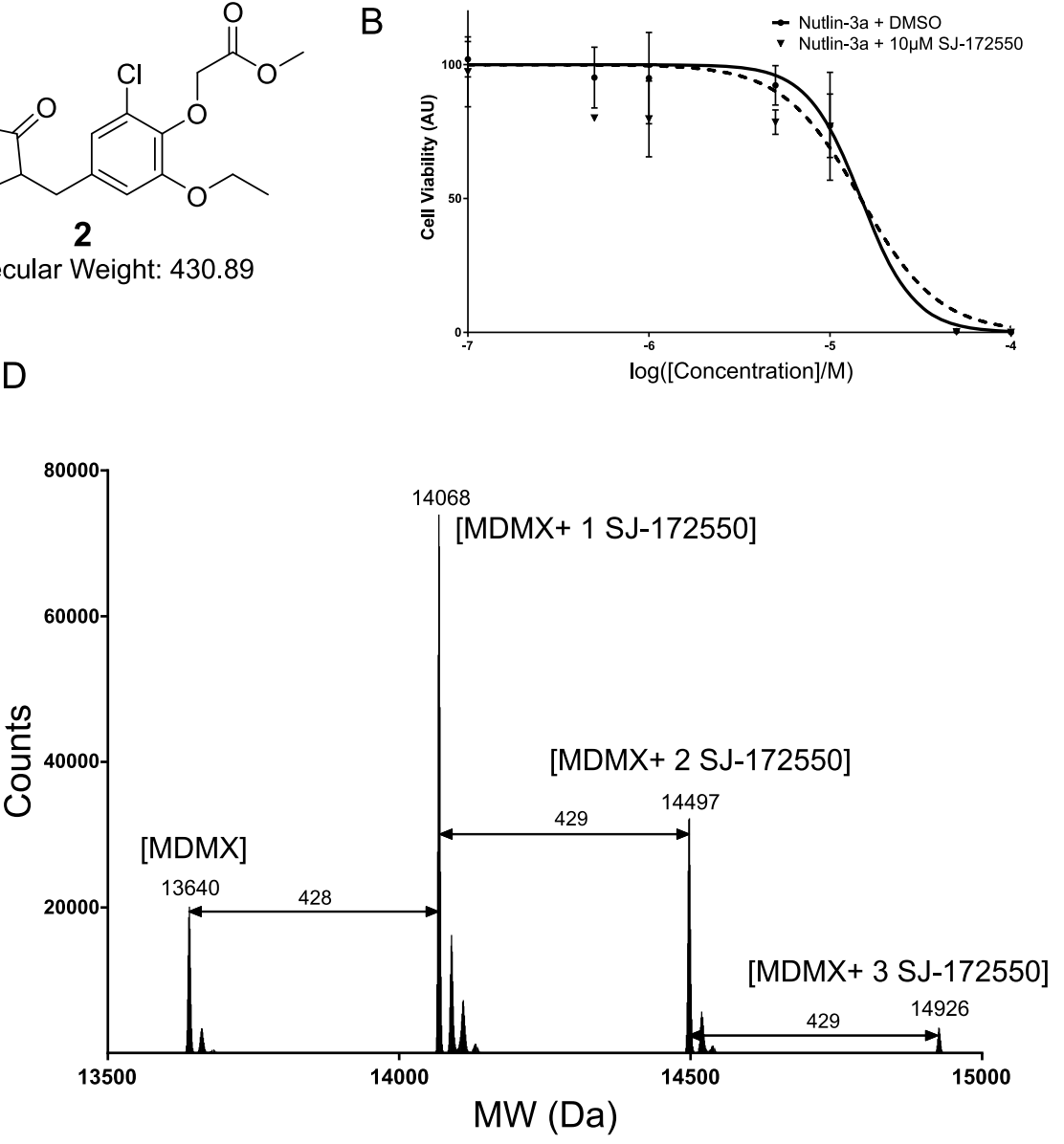

Figure 1. Evaluation of SJ-172550 on cell viability and binding to recombinant MDMX. (A) The structure of SJ-172550 (left) and its reduced analogue, SJ-Reduced (right). (B) In U2OS, $10 \mu \mathrm{M}$ of SJ-172550 does not alter cancer cell sensitivity toward Nutlin-3a (data representative for two independent experiments, $n=2$ ). (C) Isothermal titration calorimetry data in HEPES-NaCl buffer indicate that SJ-172550 is a weak binder of MDMX, with a $K_{\mathrm{d}}$ value of $>13 \mu \mathrm{M}$. (D) MALDI-TOF data using a recombinant MDMX construct with a MW of $13.6 \mathrm{kDa}$ in $\mathrm{HEPES}-\mathrm{NaCl}$ buffer shows that SJ-172550 (MW $428.87 \mathrm{Da}$ ) can bind covalently in up to three places, in accordance with three cysteines present within the construct.

status. As a result, we decided to further investigate the compound's cellular effects and target engagement.

We first examined the potential synergistic effect of SJ172550 with Nutlin-3a in p53-competent U2OS cells. Previous results demonstrated that treatment with MDMX siRNA could sensitize U2OS cells to Nutlin-3a ${ }^{15}$ however, a combination of Nutlin-3a with 1 did not seem to exhibit any synergy, compared to Nutlin-3a-treated cells when tested in standard $72 \mathrm{~h}$ cell viability assays (Figure $1 \mathrm{~B}$ ). The approximate $\mathrm{IC}_{50}$ value for SJ-172550 alone was in the high $\mu \mathrm{M}$ range (47 $\mu \mathrm{M}$; see Figure S3 in the Supporting Information), consistent with previously reported data for Weril cells. ${ }^{16}$ Previous reports have also suggested limited solubility in aqueous buffers, ${ }^{17}$ which raises the possibility that the pharmacological effects may be caused by compound aggregates.

To assess SJ-172550 binding to the p53 binding site on MDMX, we expressed GST-tagged MDMX (1-120) in E. coli and performed isothermal titration calorimetry (ITC) after removal of the GST tag. In the absence of any reducing agents, the data indicated only weak binding with a $K_{d}$ value of $>13 \mu \mathrm{M}$ (Figure 1C) with broad peaks suggestive of a covalent interaction, consistent with previous results. ${ }^{17}$ Next, using similar conditions to that of the initial study, ${ }^{17}$ we assessed the binding of 1 to MDMX by mass spectrometry via incubation of untagged recombinant MDMX (1-120) protein with a slight excess (1:1.4) of SJ-172550 in HEPES-NaCl buffer ( $\mathrm{pH} 7.5)$ at room temperature (RT) for $1 \mathrm{~h}$. Analysis of the MALDI-TOF data indicated the presence of three covalent adducts, suggesting that SJ-172550 likely binds all three cysteine residues present in the MDMX construct (Figure 1D). Earlier reports suggested that only one cysteine present within the p53-binding domain was bound; however, the MDMX constructs used in the previous study either lacked part of the N-terminus, which contains two cysteines (residues 23111), or was still attached to GST (residues $1-185) .{ }^{17}$ The covalent mechanism of action of $\mathbf{1}$ has been attributed to the presence of the Michael acceptor moiety and a previously reported reduced analogue of $S J-172550$, herein further referred to as "SJ-Reduced" (2; see Figure 1A, right), indeed exhibited diminished affinity. ${ }^{17}$ We synthesized 2 and, consistent with expectations, could not detect any significant binding in an ITC assay (see Figure S2 in the Supporting Information). As expected, $\mathbf{2}$ also did not form any covalent adducts with MDMX, as indicated by mass spectrometry data (Figure S1 in the Supporting Information).

To examine SJ-172550s cellular target engagement, we first decided to perform a cellular thermal shift assay $(\text { CETSA })^{21}$ in U2OS cells, using a method similar to previously established 
A

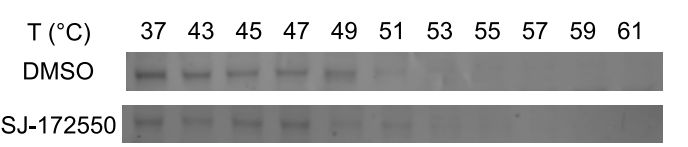

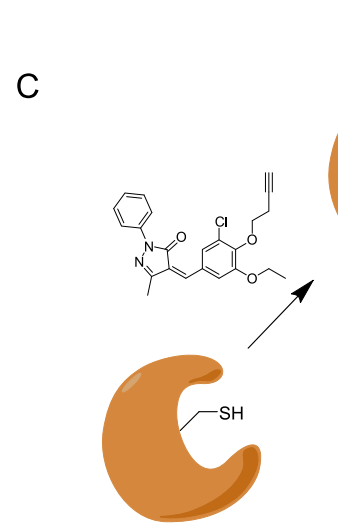

D
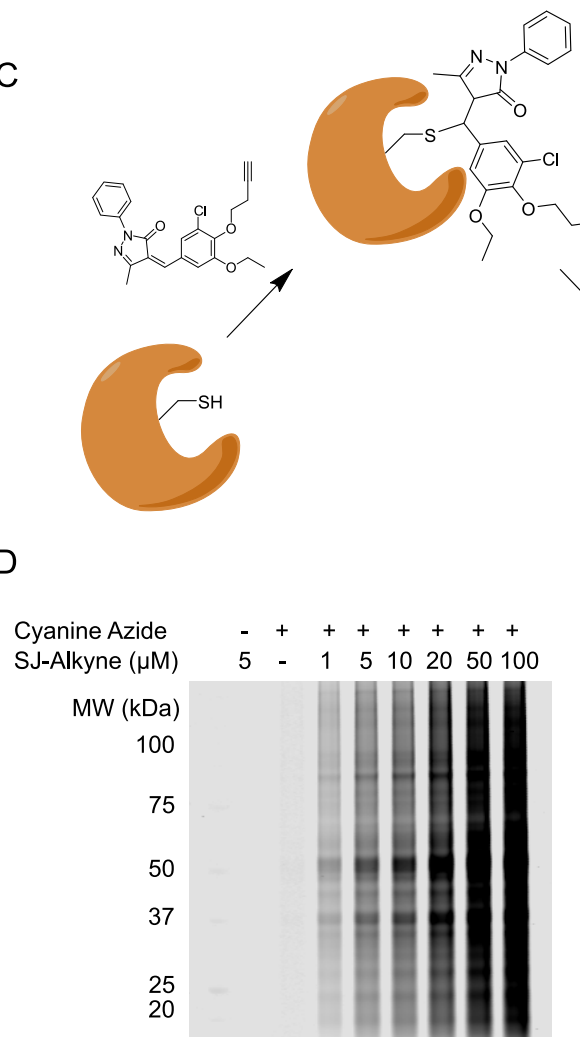

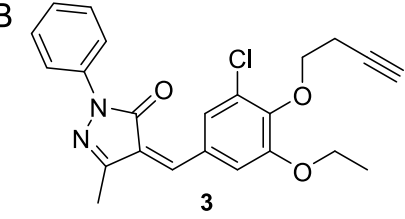

Molecular Weight: 408.88

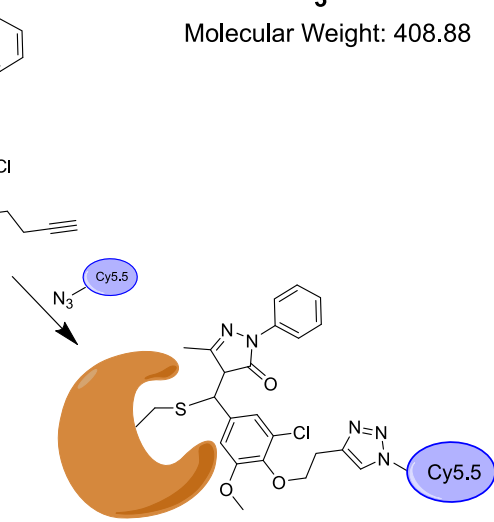

E

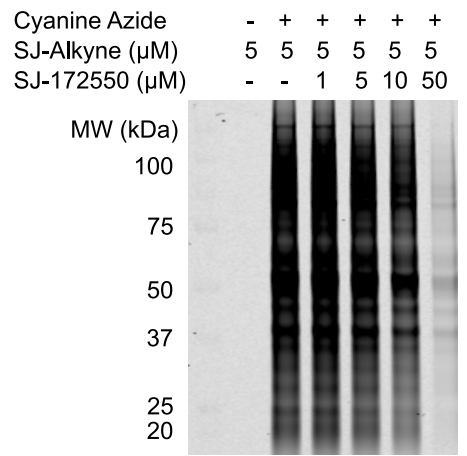

Figure 2. Target engagement, and promiscuity of SJ-172550. (A) Cellular thermal shift assay (CETSA) indicates that SJ-172550 cannot stabilize MDMX in U2OS cells, following $1 \mathrm{~h}$ of incubation (data representative for three independent experiments, $n=3$ ). (B) Structure of the affinity probe SJ-Alkyne. (C) Scheme of the biorthogonal click chemistry assay with a fluorescent dye and an SJ-Alkyne. (D) SDS-PAGE fluorescent readout indicates extensive promiscuity and nonspecific reactivity with proteins. (E) Competition with SJ-172550 reduces protein labeling of SJAlkyne in a dose-dependent manner.

protocols for stapled peptide-based MDMX inhibitors. ${ }^{22}$ Following $1 \mathrm{~h}$ of incubation with $100 \mu \mathrm{M}$ compound, we failed to detect a stabilizing effect on MDMX for SJ-172550 (Figure 2A; see Figure S8 in the Supporting Information for full blot).

Previous structure-activity relationship studies have suggested that structural modifications at $\mathrm{C} 4$ of the benzylidene moiety are tolerated. ${ }^{16}$ Using this information, we prepared a structural analogue of $\mathbf{1}$ containing an alkyne moiety ("SJAlkyne”, 3; see Figure 2B) enabling bioorthogonal coppercatalyzed alkyne-azide cycloaddition (CuAAC) reactions. $^{23}$ We first confirmed that 3 was capable of forming covalent adducts with MDMX in vitro (Figure S1 in the Supporting Information). Incubation of 3 with U2OS lysate, followed by cyanine azide click reaction, and visualization on SDS-PAGE revealed extensive labeling of proteins by the probe (Figure 2D). Competition experiments with 1 reduced the labeling of the probe in a concentration-dependent manner (Figure 2E), whereas preincubation with 2 (Figure S4 in the Supporting Information) had no appreciable effect, suggesting that the Michael acceptor moiety within $\mathbf{1}$ and 3 represents a key determinant for the cellular effects of SJ-172550. Consistent with previous data, we observed adduct formation when SJ172550 was incubated with equimolar amounts of glutathione
(Figure S5 in the Supporting Information). These results strongly suggest that SJ-172550 interacts with cellular nucleophiles in a nonspecific manner. Previous reports have also suggested that the non-nucleophilic reducing agent TCEP is unable to react with SJ-172550. ${ }^{17}$ However, while evaluating the effects of different reducing agents, we noticed that the addition of excess TCEP resulted in bleaching of the orange solution (Figure S9 in the Supporting Information), thus indicating a chemical reaction and prompting further analysis of the mixture. Indeed, LC/MS analysis confirmed the formation of a covalent adduct between the two molecules (Figure S6 in the Supporting Information). It is plausible that this adduct forms via a phospha-Michael addition reaction, as previously demonstrated for TCEP and acrylate electrophiles. $^{24}$

Interestingly, further evaluation of the MALDI-TOF data for SJ-172550 revealed an additional peak appearing over time in the chromatogram. The mass of this peak suggested the presence of a compound, which we suspected to arise from unexpected reactivity of SJ-172550 in aqueous buffers (Figure S5 in the Supporting Information). Indeed, reverse Knoevenagel condensation of arylmethylidenepyrazolinones, followed by addition of the conjugate base of the pyrazolone product onto another molecule of arylmethylidenepyrazolinone (Figure 

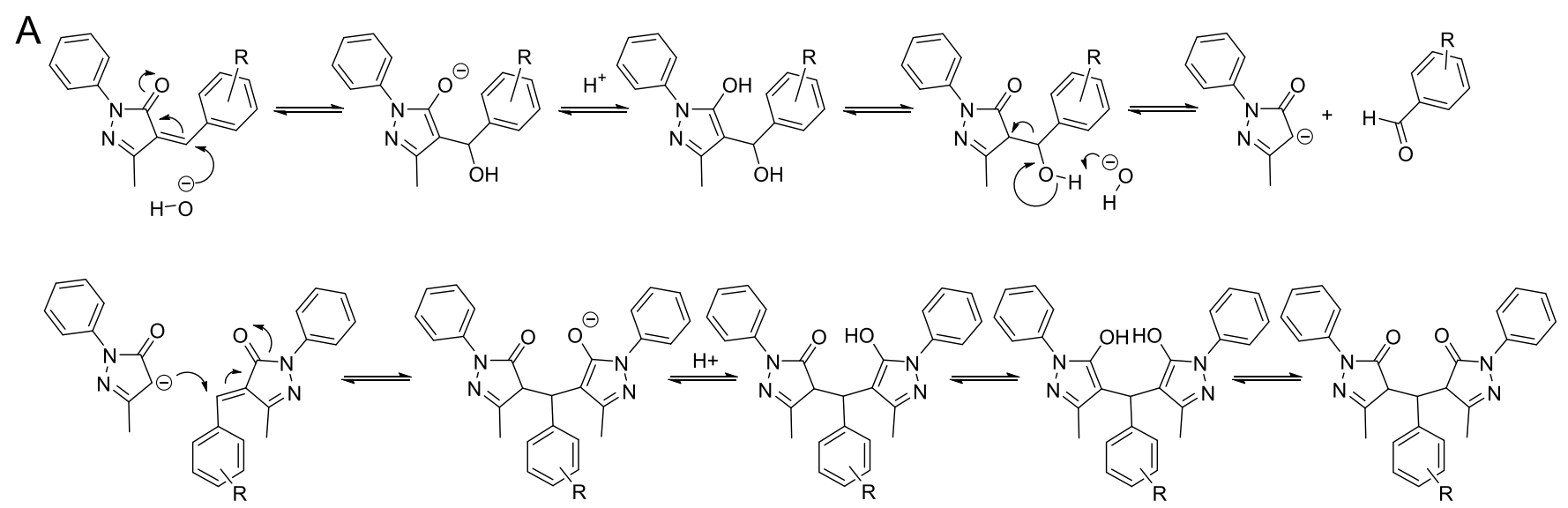

B<smiles>CCOc1cc(C(C2C(=O)N(c3ccccc3)N=C2C)C2C(=O)N(c3ccccc3)N=C2C)cc(Cl)c1OCC(=O)OC</smiles>

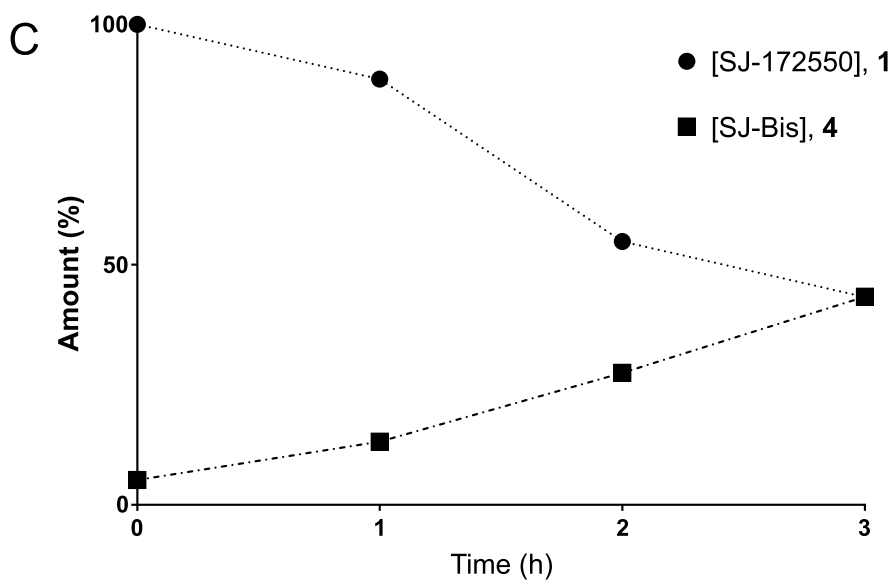

Figure 3. Instability of arylmethylidenepyrazolinones. (A) The putative generalized mechanism for the formation of arylmethylidenebispyrazolinones from arylmethylidenepyrazolinones. The initial reverse Knoevenagel reaction is followed by a Michael reaction, with the nucleophilic attack on the Michael acceptor by the enol $\pi$-electrons (favored under basic conditions, because of the deprotonation of the hydroxyl group). (B) The degradation product of SJ-172550, named SJ-Bis. (C) The kinetics of SJ-172550 degradation in HEPES buffer at $37^{\circ} \mathrm{C}$ and $\mathrm{pH} 7.5$. Nearly $10 \%$ of SJ-172550 degrades within $1 \mathrm{~h}$, with $50 \%$ of degradation occurring after 3-4 h.

$3 \mathrm{~A})$, has been reported in the literature. ${ }^{25,26}$ Different commercial batches of SJ-172550 and an original synthesized sample were tested for aqueous stability, with data from all batches indicating degradation. To confirm the identity of the byproduct, we also synthesized an authentic sample of the presumed degradation product (SJ-Bis, 4; see Figure 3B) and found that it was unable to bind MDMX in vitro (see Figure S2 in the Supporting Information). We further assayed the rate of SJ-172550 decomposition and concomitant formation of $\mathbf{4}$ by LC/MS, with significant amounts of 4 present within hours of incubation in a HEPES-NaCl buffer system ( $\mathrm{pH} 7.5)$ system at $37{ }^{\circ} \mathrm{C}$ (Figure 3C). Surprisingly, upon further inspection, we noticed that solutions of 4 which, when freshly prepared, gave a clear DMSO solution, eventually adopted an orange hue that was characteristic of SJ-172550 (Figure S9 in the Supporting Information). Indeed, further LC-MS analysis strongly suggested a dynamic equilibrium between SJ-172550 and 4 (Figure S7 in the Supporting Information). This might explain why, at very high concentrations, there is minimal competition of SJ-Alkyne with SJ-Bis in the cyanine azide click assay (Figure S4 in the Supporting Information).

Early reports already questioned the use of SJ-172550 as a chemical probe to investigate MDMX cellular function, with luciferase complementation assay data indicating that the compound is unable to disrupt the MDMX-p53 interaction in a cellular context. ${ }^{27}$ However, because of the strong interest in p53 biology and the compound's first-in-class status, SJ-172550 is still prominently featured on vendor web sites and many studies continue to use SJ-172550 as an orthogonal means to validate the effects of MDMX inhibition. Given the ongoing discussion on PAINS compounds ${ }^{28,29}$ and the desired qualities of chemical probes, ${ }^{30}$ we hope our study will aid to further increase the awareness of the potential pitfalls of reactive and potentially unstable compounds. Requirements for PAINS filtering of compounds presented in American Chemical Society (ACS) journals have recently been introduced ${ }^{31}$ and the use of various cheminformatics toolkits can help eliminate problematic scaffolds. Analysis of the molecule with the cApp algorithm ${ }^{32}$ for the presence of moieties that have the potential to cause pan-assay interference ${ }^{33}$ assigns the arylmethylidenepyrazolinone scaffold of $\mathbf{1}$ to a broad category of fivemembered heterocyclic alkylidenes, which, similarly to alkylidene rhodanines, can react with nucleophiles such as cysteines. ${ }^{34} \mathrm{~A}$ recent review on pan-assay interference compounds $^{28}$ described this scaffold as a member of the "most problematic" PAINS. Evaluation of the compound with the BadApple algorithm for weeding out potentially promiscuous molecules $^{35}$ assigns a promiscuity score of 497 to 4methylene-2-phenyl-2,4-dihydro-3H-pyrazol-3-ones, with scores above 300 being generally accepted to be considered a PAINS compound. Notably, the specificity of C646, an inhibitor of p300 containing a related furanylmethylidenepyr- 
azolinone scaffold, was recently called into question following an extensive proteomic analysis. ${ }^{36}$ Nevertheless, a short survey of the recent literature revealed the arylmethylidenepyrazolinone scaffold as a regular hit in high-throughput screening assays and virtual screens. ${ }^{37-39}$ Although we did not observe any apparent precipitation in our experiments, previous reports have also suggested that SJ-172550 may have only limited solubility in aqueous buffers. Thus, in principle, any cellular effects observed at these high concentrations could be due to nonspecific and/or aggregative effects. ${ }^{40}$

In summary, we show that SJ-172550 is a highly promiscuous compound with unclear effects on its putative cognate target MDMX in cells. In contrast to CETSA results reported for stapled peptide-based inhibitors, ${ }^{22}$ SJ-172550 did not exhibit a stabilizing effect on MDMX in intact cells. Importantly, we find that SJ-172550 rapidly decomposes in aqueous buffers within a few hours and, as such, its exclusion from screening libraries seems warranted, as recently postulated for other classic PAINS compounds, such as curcumin. ${ }^{41}$ This is not to say arylmethylidenepyrazolinones such as SJ-172550 may not be able to exhibit interesting phenotypes in living systems; however, their physicochemical properties make the interpretation of results extremely challenging and, therefore, argue against their use as tool compounds.

\section{METHODS}

All methods are described in the Supporting Information.

\section{ASSOCIATED CONTENT}

\section{S Supporting Information}

The Supporting Information is available free of charge on the ACS Publications website at DOI: 10.1021/acschembio.8b00665.

Compound characterization checklist (XLS)

Experimental procedures, compound characterizations and supplementary data (PDF)

\section{AUTHOR INFORMATION}

\section{Corresponding Authors}

*E-mail: angela.russell@chem.ox.ac.uk (A. J. Russell).

*E-mail: kilian.huber@sgc.ox.ac.uk (K. V. M. Huber).

ORCID

Jakub Stefaniak: 0000-0001-9151-4485

Andrew M. Lewis: 0000-0002-6447-354X

Sébastien R. G. Galan: 0000-0002-6241-0238

M. Paola Castaldi: 0000-0003-1959-0007

Thomas Lundbäck: 0000-0002-8145-7808

Kilian V. M. Huber: 0000-0002-1103-5300

\section{Author Contributions}

The manuscript was written through contributions of all authors. All authors have given approval to the final version of the manuscript.

\section{Funding}

The SGC is a registered charity (number 1097737) that receives funds from AbbVie, Bayer Pharma AG, Boehringer Ingelheim, Canada Foundation for Innovation, Eshelman Institute for Innovation, Genome Canada, Innovative Medicines Initiative (EU/EFPIA) [ULTRA-DD grant no. 115766], Janssen, Merck KGaA Darmstadt Germany, MSD, Novartis Pharma AG, Ontario Ministry of Economic Development and
Innovation, Pfizer, São Paulo Research Foundation-FAPESP, Takeda, and Wellcome $[106169 / \mathrm{ZZ14} / \mathrm{Z}]$. This work was supported by funding from the Engineering and Physical Sciences Research Council (EPSRC) and the Medical Research Council (MRC) [grant number EP/L016044/1].

\section{Notes}

The authors declare no competing financial interest.

\section{ACKNOWLEDGMENTS}

The authors would like to thank the entirety of the SGC, in particular N. Burgess-Brown, R. Chalk and O. Borkowska, for help with the MALDI-TOF MS experiments, as well as L. Diaz-Saez for help with the ITC experiments. In addition, the authors would like to thank J. Ward for support with the Cyanine Azide labelling experiments. Lastly, the authors would like to thank B. Xiong Tan (A*STAR, Singapore), for helpful discussion on the Western Blot CETSA.

\section{ABBREVIATIONS}

MDM2, Murine Double Minute 2; MDMX, Murine Double Minute X; FP, fluorescence polarization; HTS, highthroughput screen; MALDI-TOF MS, matrix-assisted laser desorption ionization-time-of-flight mass spectrometry; ITC, isothermal titration calorimetry; PAINS, pan assay interference compounds

\section{REFERENCES}

(1) Lane, D. P. (1992) p53, guardian of the genome. Nature 358, $15-16$.

(2) Horn, H. F., and Vousden, K. H. (2007) Coping with stress: multiple ways to activate p53. Oncogene 26, 1306-1316.

(3) Levine, A. J. (1997) p53, the Cellular Gatekeeper for Growth and Division. Cell 88, 323-331.

(4) Fridman, J. S., and Lowe, S. W. (2003) Control of apoptosis by p53. Oncogene 22, 9030-9040.

(5) Lain, S., and Lane, D. (2003) Improving cancer therapy by nongenotoxic activation of p53. Eur. J. Cancer 39, 1053-1060.

(6) Collavin, L., Lunardi, A., and Del Sal, G. (2010) p53-family proteins and their regulators: hubs and spokes in tumor suppression. Cell Death Differ. 17, 901-911.

(7) Shvarts, A., Steegenga, W. T., Riteco, N., van Laar, T., Dekker, P., Bazuine, M., van Ham, R. C. A., van der Houven van Oordt, W., Hateboer, G., Van Der Eb, A. J., and Jochemsen, A. G. (1996) MDMX: A novel p53-binding protein with some functional properties of MDM2. ЕMBO J. 15, 5349-5357.

(8) Bond, G., Hu, W., and Levine, A. (2005) MDM2 is a Central Node in the p53 Pathway: 12 Years and Counting. Curr. Cancer Drug Targets 5, 3-8.

(9) Wasylyk, C., Salvi, R., Argentini, M., Dureuil, C., Delumeau, I., Abecassis, J., Debussche, L., and Wasylyk, B. (1999) p53 mediated death of cells overexpressing MDM2 by an inhibitor of MDM2 interaction with $\mathrm{p} 53$. Oncogene 18, 1921-1934.

(10) Chène, P. (2003) Inhibiting the p53-MDM2 interaction: an important target for cancer therapy. Nat. Rev. Cancer 3, 102-109.

(11) Hardcastle, I. R., Ahmed, S. U., Atkins, H., Farnie, G., Golding, B. T., Griffin, R. J., Guyenne, S., Hutton, C., Källblad, P., Kemp, S. J., Kitching, M. S., Newell, D. R., Norbedo, S., Northen, J. S., Reid, R. J., Saravanan, K., Willems, H. M. G., and Lunec, J. (2006) Smallmolecule inhibitors of the MDM2-p53 protein-protein interaction based on an isoindolinone scaffold. J. Med. Chem. 49, 6209-6221.

(12) Ding, Q., Zhang, Z., Liu, J., Jiang, N., Zhang, J., Ross, T. M., Chu, X., Bartkovitz, D., Podlaski, F., Janson, C., Tovar, C., Filipovic, Z. M., Higgins, B., Glenn, K., Packman, K., Vassilev, L. T., and Graves, B. (2013) Discovery of RG7388, a Potent and Selective p53-MDM2 Inhibitor in Clinical Development. J. Med. Chem. 56, 5979-5983. 
(13) Sun, D., Li, Z., Rew, Y., Gribble, M., Bartberger, M. D., Beck, H. P., Canon, J., Chen, A., Chen, X., Chow, D., Deignan, J., Duquette, J., Eksterowicz, J., Fisher, B., Fox, B. M., Fu, J., Gonzalez, A. Z., Gonzalez-Lopez De Turiso, F., Houze, J. B., Huang, X., Jiang, M., Jin, L., Kayser, F., Liu, J. J., Lo, M., Long, A. M., Lucas, B., McGee, L. R., McIntosh, J., Mihalic, J., Oliner, J. D., Osgood, T., Peterson, M. L., Roveto, P., Saiki, A. Y., Shaffer, P., Toteva, M., Wang, Y., Wang, Y. C., Wortman, S., Yakowec, P., Yan, X., Ye, Q., Yu, D., Yu, M., Zhao, X., Zhou, J., Zhu, J., Olson, S. H., and Medina, J. C. (2014) Discovery of AMG 232, a Potent, Selective, and Orally Bioavailable MDM2-p53 Inhibitor in Clinical Development. J. Med. Chem. 57, 1454-1472.

(14) Vassilev, L. T., Vu, B. T., Graves, B., Carvajal, D., Podlaski, F., Filipovic, Z., Kong, N., Kammlott, U., Lukacs, C., Klein, C., Fotouhi, N., and Liu, E. A. (2004) In vivo activation of the p53 pathway by small-molecule antagonists of MDM2. Science 303, 844-848.

(15) Hu, B., Gilkes, D. M., Farooqi, B., Sebti, S. M., and Chen, J. (2006) MDMX Overexpression Prevents p53 Activation by the MDM2 Inhibitor Nutlin. J. Biol. Chem. 281, 33030-33035.

(16) Reed, D., Shen, Y., Shelat, A. A., Arnold, L. A., Ferreira, A. M., Zhu, F., Mills, N., Smithson, D. C., Regni, C. A., Bashford, D., Cicero, S. A., Schulman, B. A., Jochemsen, A. G., Guy, R. K., and Dyer, M. A. (2010) Identification and characterization of the first small molecule inhibitor of MDMX. J. Biol. Chem. 285, 10786-10796.

(17) Bista, M., Smithson, D., Pecak, A., Salinas, G., Pustelny, K., Min, J., Pirog, A., Finch, K., Zdzalik, M., Waddell, B., Wladyka, B., Kedracka-Krok, S., Dyer, M. A., Dubin, G., and Guy, R. K. (2012) On the mechanism of action of SJ-172550 in inhibiting the interaction of MDM4 and p53. PLoS One 7, e37518.

(18) Chen, R., Zhou, J., Qin, L., Chen, Y., Huang, Y., Liu, H., and Su, Z. (2017) A Fusion Protein of the p53 Transaction Domain and the p53-Binding Domain of the Oncoprotein $\mathrm{MdmX}$ as an Efficient System for High-Throughput Screening of $\mathrm{MdmX}$ Inhibitors. Biochemistry 56, 3273-3282.

(19) Soares, J., Raimundo, L., Pereira, N. A. L. L., dos Santos, D. J. V. A. V. A., Pérez, M., Queiroz, G., Leão, M., Santos, M. M. M. M., and Saraiva, L. (2015) A tryptophanol-derived oxazolopiperidone lactam is cytotoxic against tumors via inhibition of p53 interaction with murine double minute proteins. Pharmacol. Res. 95-96, 42-52.

(20) Leão, M., Gomes, S., Bessa, C., Soares, J., Raimundo, L., Monti, P., Fronza, G., Pereira, C., and Saraiva, L. (2015) Studying p53 family proteins in yeast: Induction of autophagic cell death and modulation by interactors and small molecules. Exp. Cell Res. 330, 164-177.

(21) Jafari, R., Almqvist, H., Axelsson, H., Ignatushchenko, M., Lundbäck, T., Nordlund, P., and Molina, D. M. (2014) The cellular thermal shift assay for evaluating drug target interactions in cells. Nat. Protoc. 9, 2100-2122.

(22) Tan, B. X., Brown, C. J., Ferrer, F. J., Yuen, T. Y., Quah, S. T., Chan, B. H., Jansson, A. E., Teo, H. L., Nordlund, P., and Lane, D. P. (2015) Assessing the Efficacy of Mdm2/Mdm4-Inhibiting Stapled Peptides Using Cellular Thermal Shift Assays. Sci. Rep. 5, 12116.

(23) Liang, L., and Astruc, D. (2011) The copper(I)-catalyzed alkyne-azide cycloaddition (CuAAC) "click" reaction and its applications. An overview. Coord. Chem. Rev. 255, 2933-2945.

(24) Enders, D., Saint-Dizier, A., Lannou, M.-I., and Lenzen, A. (2006) The Phospha-Michael Addition in Organic Synthesis. Eur. J. Org. Chem. 2006, 29-49.

(25) Fanghänel, E., Akhlaq, M. S., and Grossmann, N. (1985) Untersuchungen zur Hydrolysestabilität von 4-Arylmethyliden-2pyrazolin-5-onen. J. Prakt. Chem. 327, 209-219.

(26) Singh, D., and Singh, D. (1984) Syntheses of 1,3-disubstituted 4-arylidenepyrazolin-5-ones and the keto and enol forms of 4,4'arylidenebis(1,3-disubstituted pyrazolin-5-ones). J. Chem. Eng. Data $29,355-356$.

(27) Li, Y.-C., Rodewald, L. W., Hoppmann, C., Wong, E. T., Lebreton, S., Safar, P., Patek, M., Wang, L., Wertman, K. F., and Wahl, G. M. (2014) A Versatile Platform to Analyze Low-Affinity and Transient Protein-Protein Interactions in Living Cells in Real Time. Cell Rep. 9, 1946-1958.
(28) Baell, J. B., and Nissink, J. W. M. (2018) Seven Year Itch: PanAssay Interference Compounds (PAINS) in 2017-Utility and Limitations. ACS Chem. Biol. 13, 36-44.

(29) Schwarz, D. M. C., and Gestwicki, J. E. (2018) Revisiting the "Art of the Chemical Probe. ACS Chem. Biol. 13, 1109-1110.

(30) Arrowsmith, C. H., Audia, J. E., Austin, C., Baell, J., Bennett, J., Blagg, J., Bountra, C., Brennan, P. E., Brown, P. J., Bunnage, M. E., Buser-Doepner, C., Campbell, R. M., Carter, A. J., Cohen, P., Copeland, R. a., Cravatt, B., Dahlin, J. L., Dhanak, D., Edwards, A. M., Frederiksen, M., Frye, S. V., Gray, N., Grimshaw, C. E., Hepworth, D., Howe, T., Huber, K. V. M., Jin, J., Knapp, S., Kotz, J. D., Kruger, R. G., Lowe, D., Mader, M. M., Marsden, B., Mueller-Fahrnow, A., Müller, S., O'Hagan, R. C., Overington, J. P., Owen, D. R., Rosenberg, S. H., Roth, B., Ross, R., Schapira, M., Schreiber, S. L., Shoichet, B., Sundström, M., Superti-Furga, G., Taunton, J., Toledo-Sherman, L., Walpole, C., Walters, M. a., Willson, T. M., Workman, P., Young, R. N., and Zuercher, W. J. (2015) The promise and peril of chemical probes. Nat. Chem. Biol. 11, 536-541.

(31) Aldrich, C., Bertozzi, C., Georg, G. I., Kiessling, L., Lindsley, C., Liotta, D., Merz, K. M., Schepartz, A., and Wang, S. (2017) The Ecstasy and Agony of Assay Interference Compounds. J. Med. Chem. $60,2165-2168$.

(32) Amani, P., Sneyd, T., Preston, S., Young, N. D., Mason, L., Bailey, U.-M., Baell, J., Camp, D., Gasser, R. B., Gorse, A.-D., Taylor, P., and Hofmann, A. (2015) A practical Java tool for small-molecule compound appraisal. J. Cheminf. 7, 28.

(33) Baell, J. B., and Holloway, G. A. (2010) New Substructure Filters for Removal of Pan Assay Interference Compounds (PAINS) from Screening Libraries and for Their Exclusion in Bioassays. J. Med. Chem. 53, 2719-2740.

(34) Tomašić, T., and Peterlin Mašič, L. (2012) Rhodanine as a scaffold in drug discovery: a critical review of its biological activities and mechanisms of target modulation. Expert Opin. Drug Discovery 7, $549-560$

(35) Yang, J. J., Ursu, O., Lipinski, C. A., Sklar, L. A., Oprea, T. I., and Bologa, C. G. (2016) Badapple: promiscuity patterns from noisy evidence. J. Cheminf. 8, 29.

(36) Shrimp, J. H., Sorum, A. W., Garlick, J. M., Guasch, L., Nicklaus, M. C., and Meier, J. L. (2016) Characterizing the Covalent Targets of a Small Molecule Inhibitor of the Lysine Acetyltransferase P300. ACS Med. Chem. Lett. 7, 151-155.

(37) Huang, H., Yu, Y., Gao, Z., Zhang, Y., Li, C., Xu, X., Jin, H., Yan, W., Ma, R., Zhu, J., Shen, X., Jiang, H., Chen, L., and Li, J. (2012) Discovery and Optimization of 1,3,4-Trisubstituted-pyrazolone Derivatives as Novel, Potent, and Nonsteroidal Farnesoid X Receptor (FXR) Selective Antagonists. J. Med. Chem. 55, 7037-7053.

(38) Xu, Y., Smith, R., Vivoli, M., Ema, M., Goos, N., Gehrke, S., Harmer, N. J., and Wagner, G. K. (2017) Covalent inhibitors of LgtC: A blueprint for the discovery of non-substrate-like inhibitors for bacterial glycosyltransferases. Bioorg. Med. Chem. 25, 3182-3194.

(39) Dou, X., Jiang, L., Wang, Y., Jin, H., Liu, Z., and Zhang, L. (2018) Discovery of new GSK- $3 \beta$ inhibitors through structure-based virtual screening. Bioorg. Med. Chem. Lett. 28, 160-166.

(40) Davis, B. J., and Erlanson, D. A. (2013) Learning from our mistakes: the "unknown knowns" in fragment screening. Bioorg. Med. Chem. Lett. 23, 2844-52.

(41) Nelson, K. M., Dahlin, J. L., Bisson, J., Graham, J., Pauli, G. F., and Walters, M. A. (2017) The Essential Medicinal Chemistry of Curcumin. J. Med. Chem. 60, 1620-1637. 